\title{
Innovation Training-from Analogy to Deepen Comprehension and to Innovation with Modified Coaxial Electrospinning as an Example
}

\author{
Xiao-Yan Li*, Tao Hai, Yitao Wang, Xiao Chen, Yiyong He, Dengguang Yu \\ School of Medical Instrument and Food Engineering \\ University of Shanghai for Science and Technology \\ 516 Jungong Road, Shanghai 200093, China \\ lixiaoyan@usst.edu.cn \\ *Corresponding author
}

\begin{abstract}
Innovation ability is very important for college students when they walk into society to begin their carriers. How to cultivate their innovation ability is a big challenge to their teachers, particularly those who teach senior students. This paper develops a new method to carry out innovation training for college students. In this method, improved coaxial electrospinning is used as an advanced nanotechnology model and analogy is used as a logic method. The developed method not only can promote college students to deepen their comprehension of the electrospinning process, but also can derive two approaches of implementing innovations, one is the difference inspiration innovation, and the other is integration innovation. Based on existing method and modern advanced technologies, a series of other methods can be similarly developed for innovation training for college students in higher school.
\end{abstract}

Keywords-Innovation; Analogy; Modified coaxial electrospinning; Integration innovation; Difference inspiration innovation

\section{INTRODUCTION}

Innovation, often referred to as a "new idea, device or method", can be defined as something original, more effective and new, which "breaks into" the society or market. Apparently, it is more apt to involve the practical implementation of an invention to generate a meaningful impact in the market or society [1]. Frequently, Innovation can be manifested through the engineering process, when the problem being solved is of a technical or scientific nature.

In higher education, how to make the college students grasp the advanced technologies, improve their innovation capability often comprises one of the most important problems in their classes. Innovation skills are practically the types of skills that allow the students to become innovative in what they do. These are usually a combination of cognitive skills (such as the ability to think creatively and critically), behavioural skills (such as the ability to solve problems), functional skills (such as basic skills such as writing, reading and numeracy) and technical skills (such as research techniques, project management, or IT engineering) [2]. For the senior college students, who have grasp a series of cognitive skills after hard study during their their lower grade of the university, how to train their comprehensive and innovation ability and what kinds of materials are suitable for this goal are big concerns to the professional teachers.

For students majoring in materials science and engineering, some modern engineering methods and technologies for creating new functional nanomaterials are familiar to them. Knowing what are them should be only the first step. The second step should be further deepening the understandings through practices, comparison and analogy. And the third step should be some innovations are generated based on their owns experiences, a diagram is shown in Fig. 1. During these processes, analogy can be one of the most useful methods that make the education and study more efficaciously.

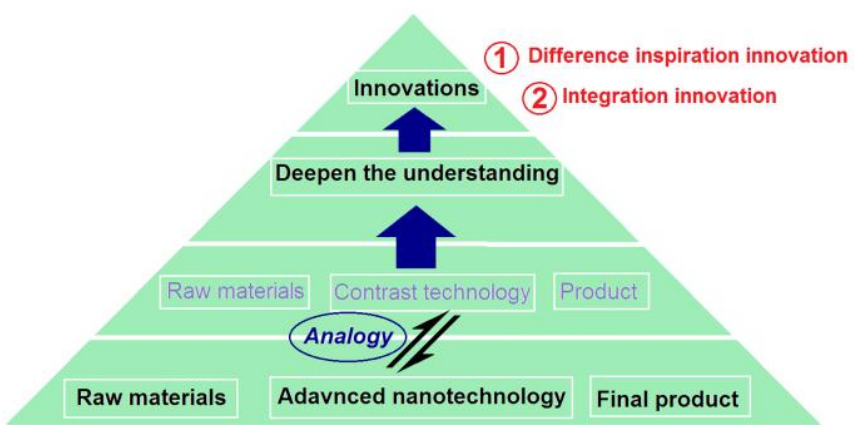

Fig. 1 A diagram showing the exploitation of advanced technology as teaching materials for training college students' innovation ability.

Analogy is a cognitive process of transferring information or meaning from a particular subject (the analog or source) to another (the target). It can play a significant role in problem solving, as well as creativity, invention, generalization, and communication. It is often thought of that analogy is "the core of cognition" and comparison is one of the most important analogical languages [3]. For college students, the training of analogical comparisons of different kinds of advanced technologies is to deepen their knowledge about these technologies and to train their innovation capabilities. 
Based on the above-mentioned knowledge, here, we develop a new method for carrying out innovation training to the college students, in which the modified coaxial electrospinning is exploited as an advanced nanotechnology model and analogy is utilized as a logic method. The method not only promote the students to deepen their comprehension on this "top-down" nanofabrication process, but also two approaches can be drawn out for implementing innovations, one is the difference inspiration innovation, and another is integration innovation.

\section{ANALOGY TO DEEPEN COMPREHENSION ON THE EHDA PROCESSES}

The modified coaxial electrospinning is a brand-new electrohydrodynamic atomization (EHDA) process, in which double fluids are exploited in a core-sheath combined manner, and particularly, the sheath working fluid has no any electrospinnability [4-9]. Because the electrospinnable fluids in the world is very limited, only over 100 types by estimation, but the un-spinnable liquids are infinite (including all types of solutions, solvents, emulsions, suspensions and even slurry), thus, the modified coaxial electrospinning process can greatly expand the capability of this "top-down" fabrication process in generation of nanoproducts

From a standpoint of technological method, the modified coaxial electrospinning can be explained to the students with an analogy of other related "top-down" nanofabrication methods [10-15]. Shown in Fig. 2, the single-fluid blending electrospinning, the single-fluid electrospraying, and also the traditional coaxial electrospinning (using an electrospinnable solution as the sheath working fluid) are the peer methods of the modified coaxial electrospinning. All these technologies belong to the electrohydrodynamic atomization (EHDA) methods, in which electrostatic energy is explored to solidify the working fluids and meanwhile give the final products a certain outer morphology (such as linear fibers and round particles) and inner complex nanostructures (such as coresheath and nanocoating). For the college students, their experiences in the single-fluid electrospinning and electrospraying can make them understand and implement the modified coaxial electrospinning more facile.

In the implementation of a single-fluid electrospinning or electrospraying, the variables that can be utilized for manipulating the working processes and also the quality of the final products can be divided into three categories (Fig. 3). One is the environmental conditions, which includes temperature, apparent humidity and also the potential vacuum. The second is the properties of the working fluid, i.e. its viscosity, surface tension, conductivity, elasticity and so on. The third is the working conditions for carrying out the singlefluid electrospinning/electrospraying processes, which includes at least the applied voltage, the product-accepted distance from the nozzles, the flow rate of the working fluid, and also the temperature or pressure of the working fluid provided the fluid is driven by compressed air.

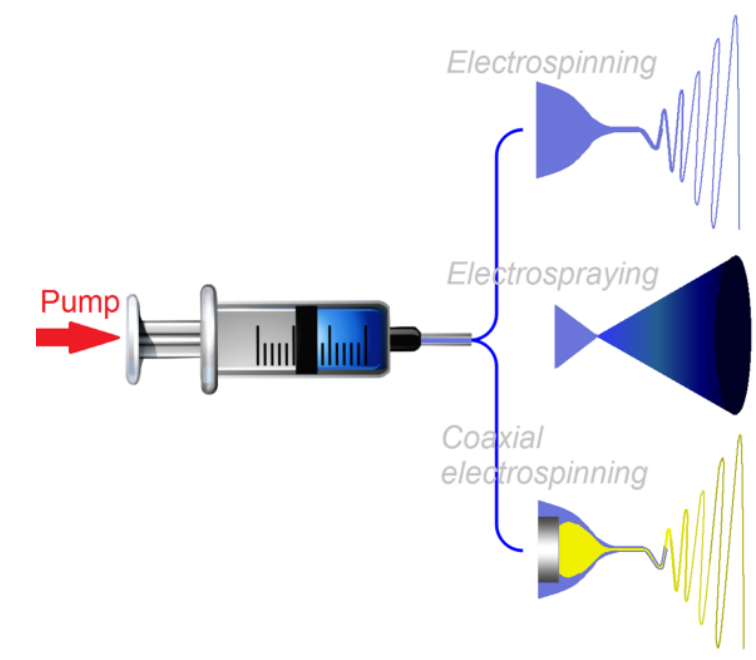

Fig. 2 The electrohydrpdynamic atomization processes: electrospinning, electrospraying, and the modified coaxial electrospinning.

For the college students who have experiences in the single-fluid electrospinning/electrospraying, the comprehension and implementation of the modified coaxial electrospinning should be a piece of cake through analogy. All the conditions are similar except that two working fluids are exploited simultaneously with the sheath fluid is un-spinnable liquid. The experimental parameters are similar, particularly the applied polymer types and their concentrations. Based on comparisons, the students can not only select experimental conditions to conduct the modified coaxial electrospinning processes, but also should deepen their comprehensions on the single-fluid blending electrospinning processes.

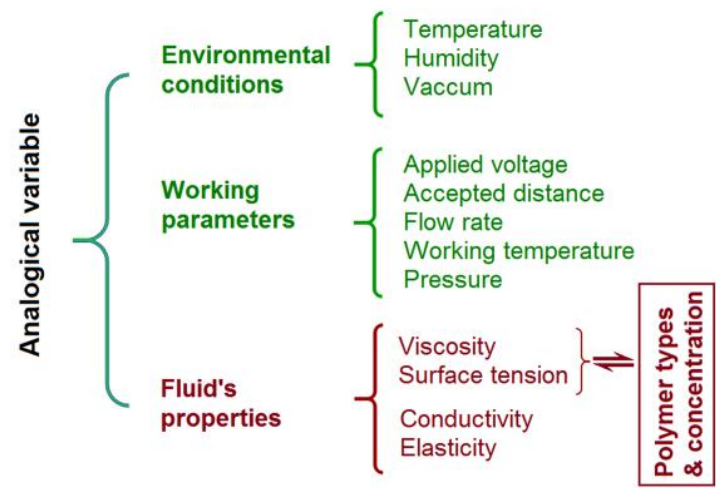

Fig. 3 Analogy to deepen comprehension on the EHDA processes. 


\section{DIFFERENCE INSPIRATION INNOVATION--THE INNOVATION DERIVED FROM THE DIFFERENCES BETWEEN THESE TECHNOLOGIES}

Although different kinds of EHDA processes are very similar in the working processes and using similar apparatus, their differences in the final products are clear. And in a strict meaning, many subtle differences can be discerned out from their working processes. These differences can be explored for provoke new innovations, i.e. difference inspiration innovation.

The modified coaxial electrospinning is a typical example of difference inspiration innovation. Through comparisons, it is clear that the single-fluid electrospinning and electrospraying are difference in that they utilize working fluids with different filament-forming properties. The former utilizes those fluid having fine electrospinnability [16-20], whereas the later exploits fluids without any filament-forming properties [21-27]. However, their difference suggests that a new EHDA process, in which both the electrospinnable and the un-spinnable working fluids are combined together and treated simultaneously. Thus, the coaxial electrospinning process can be upgraded from the traditional one (the sheath fluid must be electrospinnable, whereas the core fluid has or hasn't filament-forming properties) to the modified one with un-spinnable sheath liquid.

For the single-fluid blending electrospinning process, the electrospun products are mainly the linear nanofibers, which deposit on the collectors in a random manner and form a nonwoven nanofiber mat (Fig. 4). For the single-fluid electrospraying process, the electrosprayed products are mainly the round particles. Sometimes, when the working fluid can not be solidified, wet film will be created. Thus, the differences among the treated working fluids in these EHDA processes (such as electrospinnable, un-spinnable, solidifiable and un-solidifiable) determine that different kinds of products would be fabricated (Fig. 4). Certainly, these differences would inspire new types of innovation products. For example, the electrospun nanofibers can be combined with the electrosprayed particles through different manners, one is the simultaneously implementations of a single-fluid electrospinning and electrospraying, and another is the modified coaxial electrospinning [28-29].

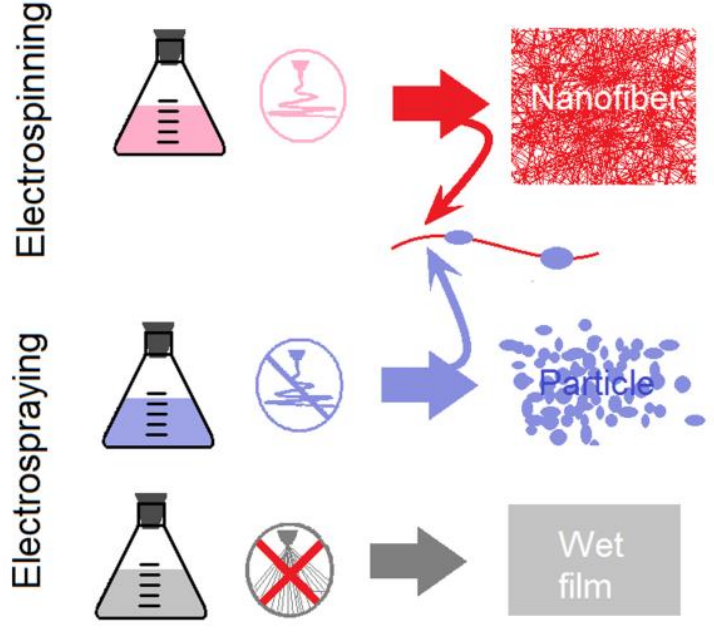

Fig. 4 The difference inspiration innovation from the EHDA products.

\section{THE INTEGRATION INNOVATION}

Needless to say, in the scientific field, that achieving mastery through a comprehensive study of the subject can lead to innovation and skill comes from practice. For the college students, it is a possible manner to provoke them to try innovation through the integration of different kinds of technologies.

Electrospinning, to some extent, is an integration innovation. Shown in Fig.5, there are a series of spinning technologies, such as wet spinning, dry spinning, dry-jet-wet spinning, melt spinning and gel spinning, in which mechanical forces are exploited to draw the working fluids in the liquid bath to form fibers. On the other hand, EHDA methods take advantage of electrostatic energy to treat liquids, by which solid products can be generated after the evaporation of solvents in the working fluid. Thus, the integration of "spinning" and "EHDA" leads to the electrospinning process, which is initially called electrostatic spinning. To be more accurate, electrospinning (particularly solution electrospinning) is a combination of electrospraying and wet spinning.

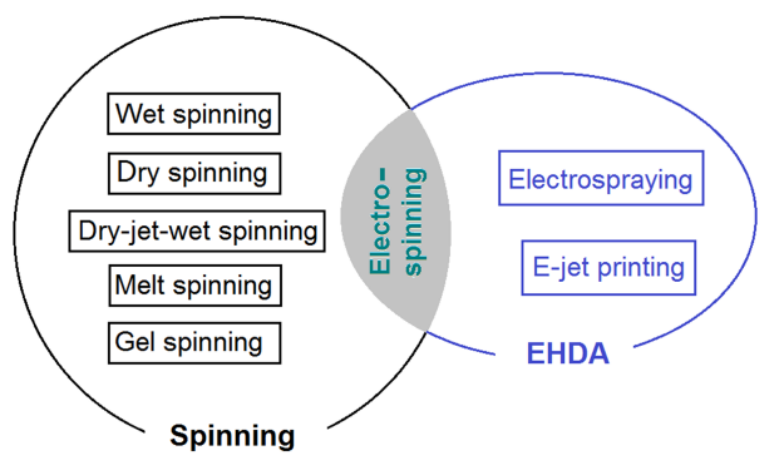

Fig. 5 The integration innovation of electrospinning from "spinning" and "EHDA". 


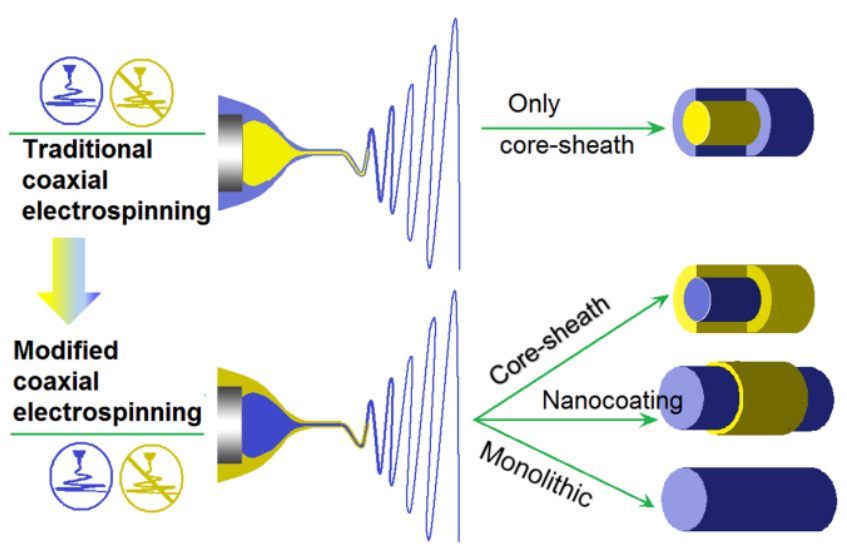

Fig. 6 The integration innovation of the modified coaxial electrospinning from "traditional coaxial electrospinning" and electrospraying.

Shown in Fig. 6, the further integration of "traditional coaxial electrospinning" with electrospraying can lead to the innovation about the new modified coaxial electrospinning process. On one hand, it has the property of the traditional coaxial electrospinning, with two working fluids treated simultaneously in a core-sheath combined manner. On the other hand, it also share some properties of the single-fluid electrospraying processes, for example, the utilization of unspinnable liquids as working fluids, and the exploitation of electrostatic energy for solidifying the working fluids. Meanwhile, hybrids composed of electrosprayed particles and electrospun nanofibers will be generated when an excessive sheath fluid flow rate is provided.

\section{SUMMARY}

With the modified coaxial electrospinning as an advanced nanotechnology model and analogy as a logic method, a new method is successfully developed for conducting innovation training to the senior college students in high school. Through effective implementation of the developed method, the students are not only able to deepen their comprehension on the electrospinning process and the related materials science and engineering, but also they can learn how to initiate an innovation through comparison and analogy. Two useful approaches, i.e. difference inspiration innovation and integration innovation, should be useful for them to carry out innovations in their study and future carriers. Based on the present method and the modern advanced technologies, a series of other methods can be similarly developed for innovation training on the college students in higher school.

\section{ACKNOWLEDGMENT}

The financial supports from the following projects are appreciated: the Shanghai Education Science Research Project (C17058), the National Natural Science Foundation of China (No. 51373101), the 2017 Graduate curriculum reform project in USST, and the College Student Innovation Project of USST (Nos. SH2018).

\section{REFERENCES}

[1] M.D. Walker, and D. Garlovsky, "Going with the flow: Using analogies to explain electric circuits," School Sci. Rev., vol. 97, pp. 51-58, 2016.

[2] E. Miron, M. Erez, and E. Naveh, "Do personal characteristics and cultural values that promote innovation, quality, and efficiency compete or complement each other?" J. Organisational Behaviour, vol. 25, pp.175-199, 2004.

[3] M. Koszowski, "Multiple functions of analogical reasoning in science and everyday life," Polish Sociological Rev., vol. 2017, pp. 4-10, 2017.

[4] Y.H. Wu, D.G. Yu, H.P. Li, X.Y. Wu, and X.Y. Li, "Medicated structural PVP/PEG composites fabricated using coaxial electrospinning," e-Polymers, vol.17, pp.39-44, January 2017.

[5] J.J. Li, Chen Yang, Hai-Peng Li, Qing Wang, and Deng-Guang Yu, "Oral controlled release in accordance with drug adsorption biological rhythm provided by an electrospun structural amorphous solid dispersion," J. Control. Release, vol.259, pp.e61-e62, 2017.

[6] X. Liu, W. Shao, M. Luo, J. Bian, D.G. Yu, "Electrospun blank nanocoating for improved sustained release profiles from medicated gliadin nanofibers," Nanomaterials, vol.8, Article ID 184 (11 pages), 2018.

[7] Y.Y. Yang, Z.P. Liu, D.G. Yu, K. Wang, P. Liu, X. Chen, "Colonspecific pulsatile drug release provided by electrospun shellac nanocoating on hydrophilic amorphous composites," Int. J. Nanomed., vol.2018, DOI: 10.2147/IJN.S154849, 2018.

[8] Y.H. WU, C. Yang, X.Y. Li, J.Y. Zhu, and D.G. Yu, "Medicated nanofibers fabricated using $\mathrm{NaCl}$ solutions as shell fluids in a modified coaxial electrospinning," J. Nanomater., vol.2016, Article ID 8970213, 2016.

[9] Y. Xu, J.J. Li, D.G. Yu, G.R. Williams, J.H. Yang, and X. Wang, "Influence of the drug distribution in electrospun gliadin fibers on drugrelease behavior," Eur. J. Pharm. Sci., vol.106, pp.422-430, August 2017.

[10] H.F. Wen, C. Yang, D.G. Yu, X.Y. Li, and D.F. Zhang, "Electrospun zein nanoribbons for treatment of lead-contained wastewater," Chem. Eng. J., vol.290, pp.263-272, April 2016.

[11] Z. Zhang, W. Li, G. Wang, Y.L. Qu, and D.G. Yu, "Electrospun 4th generation solid dispersions of poorly water-soluble drug utilizing two different processes," J. Nanomater. Vol.2018, Article ID 2012140, 2018.

[12] Q. Wang, D.G. Yu, S.Y. Zhou, C. Li, and M. Zhao, "Fabrication of amorphous electrospun medicated-nanocomposites using a Teflonbased concentric spinneret," e-Polymer, vol.18, pp.3-11, 2018.

[13] Q. Wang, D.G. Yu, L.L. Zhang, X.K. Liu, Y.C. Deng, and M. Zhao, "Electrospun hypromellose-based hydrophilic composites for rapid dissolution of poorly water-soluble drug," Carbohydr. Polym., vol.174, pp.617-625, Oct, 2017.

[14] M. Jin, D.G. Yu, C.F.G.C. Geraldes, G.R. Williams, and S.W.A. Bligh, "Theranostic fibers for simultaneous imaging and drug delivery," Mol. Pharm., vol.13, pp.2457-2465, July 2016.

[15] C. Yang, D.G. Yu, D. Pan, X.K. Liu, X. Wang, S.W.A. Bligh, et al, "Electrospun $\mathrm{pH}$-sensitive core-shell polymer nanocomposites fabricated using a tri-axial processes," Acta Biomater., vol.35, pp.77-86, April 2016.

[16] D.G. Yu, C. Yang, M. Jin, G.R. Williams, H. Zou, X. Wang, et al, "Medicated Janus fibers fabricated using a Teflon-coated side-by-side spinneret," Colloid. Surface B, vol.138, pp.110-116, Feburary 2016.

[17] D.G. Yu, H.P. Li, C. Yang, J.J. Li, Q. Wang, and G.R. Williams, "Double-pulsatile release core-shell fibers fabricated using modified tri-axial electrospinning," J. Control. Release, vol.259, pp.e24-e25, 2017.

[18] Y.H. WU, H.P. Li, X.X. Shi, J. Wan, Y.F. Liu, and D.G. Yu, "Effective utilization of the electrostatic repulsion for improved alignment of electrospun nanofibers," J. Nanomater., vol.2016, Article ID2067383, 2016.

[19] G.Z. Yang, H.P. Li, J.H. Yang, J. Wan, and D.G. Yu, "Influence of working temperature on the formation of electrospun polymer nanofibers," Nanoscale Res. Lett., vol.12, Article 15, January 2017.

[20] G.Z. Yang, J.J. Li, D.G. Yu, M.F. He, J.H. Yang, and G.R. Williams, "Nanosized sustained-release drug depots fabricated using modified triaxial electrospinning," Acta Biomater., vol.53, pp.233-241, April 2017. 
[21] Y.H. Wu, D.G. Yu, J.J. Li, Q. Wang, H.P. Li, and X.Y. Li, "Medicated multiple-component polymeric nanocomposites fabricated using electrospraying," Polym. Polym. Compos., vol.25, pp.57-62, 2017.

[22] X.Y. Li, Z.B. Zheng, D.G. Yu, X.K. Liu, Y.L. Qu, and H.L. Li, "Electrosprayed sperical ethylcellulose nanoparticles for an improved sustained-release profile of anticancer drug," Cellulose, vol.24, pp.5551-5564, 2017.

[23] Z.P. Liu, Y.Y. Zhang, D.G. Yu, D. Wu, and H.L. Li, "Fabrication of sustained-release zein nanoparticles via modified coaxial electrospraying," Chem. Eng. J., vol.334, pp.807-816, 2018.

[24] Y.Y. Yang, M. Zhang, Z.P. Liu, K. Wang, and D.G. Yu, "Meletin sustained-release gliadin nanoparticles prepared via solvent surface modification on blending electrospraying," App. Surf. Sci., vol.434, pp.1040-1047, 2018.

[25] K. Wang, H.F. Wen, D.G. Yu, Y. Yang, and D.F. Zhang, "Electrosprayed hydrophilic nanocomposites coated with shellac for colon-specific delayed drug delivery," Mater. Design, vol.143, pp.248255, 2018.

[26] Z.P. Liu, L.L. Zhang, Y.Y. Yang, D. Wu,G. Jiang, and D.G. Yu, "Preparing composite nanoparticles for immediate drug release by modifying electrohydrodynamic interfaces during electrospraying," Powd. Technol., vol.327, pp.179-187, 2018.

[27] K. Wang, X.K. Liu, X.H. Chen, D.G. Yu, Y.Y. Yang, and P. Liu, "Electrospun hydrophilic Janus nanocomposites for the rapid onset of therapeutic action of helicid," ACS Appl. Mater. Interfaces, vol.10, pp.2859-2867, 2018.

[28] Q. Wang, H.P. Li, C. Yang, J.J. Li, and D.G. Yu, "Beads-on-a-string amorphous solid dispersion fabricated using a modified coaxial electrospinning,” J. Control. Release, vol.259, pp.e111-e112, 2017.

[29] D.G. Yu, J.J. Li, M. Zhang, and G.R. Williams, "High-quality Janus nanofibers prepared using three-fluid electrospinning," Chem. Commun., vol.53, pp.4542-4545, April 2017. 